\title{
O MITO DE AFRODITE EM CONTRAPONTO AO MITO DA BELEZA NA CONTEMPORANEIDADE
}

\author{
Adriano Carvalho Viana ${ }^{81}$ \\ Marta Cirino ${ }^{82}$
}

Resumo: O texto analisa o mito da deusa Afrodite e seus desdobramentos na mitologia grega, a importância da beleza no viés físico e platônico. Noutro ponto, verifica-se a desmistificação do ideal de beleza, uma beleza mutável, ditada pela mídia, esse estereótipo culmina em um mercado ilusório e distorcido, porque a beleza ideal é ideal porque não existe, além de acompanhar alguns aspectos sociais e de repercussão pertinente. A partir de uma metodologia bibliográfica, objetivou-se correlacionar o tema beleza a partir de leituras filosóficas, feminista e médica (estética), de modo a propor uma reflexão à sociedade, em especial às mulheres, para que tenham ciência do fenômeno beleza.

Palavras-chave: Beleza, Mito, Figura Feminina, Empoderamento.

ABSTRACT: The article analyzes the myth of the goddess Aphrodite and her developments in Greek mythology, the importance of beauty in physical and platonic bias. Elsewhere, it occurs the demystification of the ideal beauty standard, a mutable beauty, dictated by the media. This stereotype culminates in an illusory and distorted market, because "ideal beauty standard is ideal because it does not exist", following some social aspects and in a relevant repercussion. From a bibliographic methodology, objectified correlate the theme of beauty from philosophical, feminist and medical (aesthetic) readings, in order to propose a reflection to society, especially women, so that they are aware of the beauty phenomenon.

Keywords: Beauty, Myth, Female Figure, Empowerment.

\section{INTRODUÇÃO}

O presente trabalho objetiva analisar o ser mulher na Contemporaneidade, que não é tarefa fácil, pois vinculou-se a ideia da indústria da beleza, em que o ideal é seguir uma figura estereotipa magra, com seios avantajados e sempre maquiada, movimentando assim o mercado estético.

Não ocasionalmente a mulher deve alastrar seus traços femininos e fazer com que sua figura seja valorizada, porém o excesso leva a erros grotescos. Desta feita, averiguou-se uma bibliografia que perpassou pelo mito de Afrodite, a conhecida deusa do amor, e um contraponto com o mito da beleza, escrito por Naomi Wolf.

\footnotetext{
${ }^{81}$ Graduado em Filosofia pelo Centro Universitário Assunção. Graduando em Direito pelo Instituto Florence de Ensino Superior- Florence. Graduando em Teologia pelo Centro Internacional- UNINTER. Mestrando em Letras pela Universidade Federal do Maranhão. E-mail: adrianocrsp@gmail.com

82 Graduada em Filosofia pelo Centro Universitário Assunção. Pós-Graduando em História Civilização e Pensamento Medieval. Professora de Filosofia no ensino médio da rede estadual. E-mail: filosofamcirino@gmail.com
} 
A estética corporal (a beleza) vem sendo atribuída às mulheres e que, por isso mesmo, na lógica do senso comum (lugar onde se difundem mais livremente todos os mitos sociais) apresentar elevada preocupação com a aparência é claramente "coisa de mulher".

O resultado objetivo dessa atribuição historicamente acumulada é que, contemporaneamente, os cuidados com a aparência são de fato uma preocupação eminentemente feminina e, neste sentido, em grande medida, é por meio de sua agência que esse "mito" continua a ser reproduzido.

Desta forma, a mulher não pode ser entendida como um mito, ou um objeto, mas sim com suas próprias definições e características, isto é, sua identidade. Vamos adentrar nessa caminhada e verificarmos como podemos ter soluções para um problema que não é tão velho, quanto novo e que perpassa todos os momentos da construção do ser mulher.

\section{O CONTEXTO HISTÓRICO DO SURGIMENTO DO MITO}

Para compreendemos o significado de mito, precisamos partir do ponto de vista etimológico da palavra, entender que o mito é uma narrativa em função de um conjunto de transmissão oral, daquilo que é memorável.

Na Grécia Antiga, os poetas se encarregavam dessa transmissão ao povo e faziam com maestria, a mitologia grega segundo Brisson (2014,p.37), "tinha caráter de veracidade, o povo nem questionava, se eram verdadeiras as histórias ou não, acreditavam fielmente no mito, até como conto sagrado de muitos significados, que ensinavam a eles sobre todas as coisas, da maneira que se apresentam".

Para o povo grego, o mito representava o modo de vida, não era entendido como conteúdo simbólico, tal como é, mas como uma realidade vivida. Acreditavam que seus antepassados, viveram os mitos que eles vivem no presente da sua época. Um dos aspectos do mito é relatar algo do passado, inclusive acontecimentos sobrenaturais, incluindo o comportamento humano como Brisson nos ensina:

\footnotetext{
Em suma, o mito é esse discurso pelo qual é comunicada toda informação sobre o passado longínquo, conservada na memória de uma dada coletividade que a transmite oralmente de uma geração a outra, tenha esse discurso sido elaborado por um técnico da comunicação ou não. (BRISSON, 2014, p.42).
}

Os mitos também serviam para explicar os fenômenos da natureza, a origem do universo, a origem e o destino do homem, além dos fatos da realidade. A maior importância do mito é dar significado e valorizar a existência, pois um mundo desprovido de mitos será um mundo sem significados.

O mundo é representado através do mito pelas ações e representações dos deuses, isso o fundamenta, e atribui a ele um sentido. Pode-se dizer então que o mito não é mera invenção, uma ficção narrada, a fim de explicar alguma coisa, mas uma realidade que eterniza, organizando o existir do homem. Os mitos são constituídos culturalmente, desenvolvendo uma capacidade simbólica de uma determinada cultura, a qual ocorre no "discurso", ou seja, na língua, pois todos os grupos humanos dispõem de uma 
linguagem, e esse é o maior recurso de expressão com representação simbólica do homem, como nos ensina Abbagnano:

Mito é uma forma autônoma de pensamento e de vida. Nesse sentido, a validade e a função do mito não são secundárias e subordinadas em relação ao conhecimento racional, mas originárias e primárias, situandose num plano diferente do plano do intelecto, porém dotado de igual dignidade. (ABBAGNANO, 2007, p. 785).

Segundo Jaeger (2003, p.89) "o mito era um assunto de interesse ilimitado do povo grego antigo, pois o mito incitava uma infinidade de narrações, reflexões e constituíam toda a filosofia daqueles homens, assim o povo inconscientemente escolhia assuntos das sagas que manifestavam a própria orientação espiritual deles".

Hesíodo, o grande poeta campesino, narrador, declamava os seus poemas que eram verdadeiros mitos, na intenção de agradar o povo do campo, ouvinte em massa da época; seus poemas permitiramnos conhecer com clareza o tesouro espiritual desses camponeses. Os poemas preferidos deles são os mitos que exprimem a concepção realista da vida e pessimista daquela classe camponesa, aquilo que retrata as causas das misérias e necessidades da vida social, que tanto os oprimem.

Com o mito de Prometeu, Hesíodo encontra a salvação para o problema do cansaço e dos sofrimentos da vida humana; o mito de pandora que é alheio ao pensamento cavalheiresco, exprimiu a concepção triste e prosaica da mulher como fonte de todos os amantes.

Jaeger relata (2003, p.90), que "Hesíodo foi o primeiro homem a popularizar essas histórias dentre o povo grego, situando-os no contexto social e filosófico". Assim a atitude original do homem perante a existência ganha forma nos mitos.

Por isso é que todas as classes sociais possuem seu próprio tesouro de mitos; com os mitos o povo guarda sua antiga sabedoria prática, adquirida pela experiência e passa essa sabedoria de gerações em gerações, conselhos profissionais, normas morais e sociais, concentradas em fórmulas breves de maneira que seja possível conservar na memória.

\section{O MITO DE AFRODITE}

Segundo a narrativa da mitologia grega, dois deuses do Olimpo, sendo eles, Urano e Cronos seu próprio filho, em virtude de uma discórdia, de poder, Cronos decepa os testículos do pai, o soberano deus dos deuses e dos homens, Urano perde então o seu reino e sua genitália, a qual cai das nuvens sobre as águas do mar, perto de Citera, formando uma grande espuma branca, na verdade essa espuma seria o esperma de Urano que se movimenta nas águas. "De repente, de dentro da branquíssima espuma, saltou uma jovem a filha de Urano, Afrodite, a mais bela moça, a mais bela deusa que já surgiu no mundo" (MENELAOS STEPHANIDES, 2011, p. 58) 
Nesse momento, portanto, a natureza toda reage alegremente diante da contemplação de tamanha formosura da belíssima e mais nova deusa, que surgia do mar. Os peixes, os pássaros e até mesmo as ondas, se movimentaram na saudação à deusa. Perante o ocorrido, as aves marinhas, todas muito alegres, gorjeando, de imediato levaram uma enorme concha em forma de um carro marinho para conduzir a deusa até a ilha de Chipre. Ao atracar na ilha, a deusa foi recebida com fascínio e exultação por todos os seres do universo. Por onde a deusa passava, provocava e irradiava alegria e vida, flores brotavam e perfumavam o ar, pássaros que cantavam em festejos, as feras das florestas se tornavam mansas e saltitavam felizes ao seu redor.

Afrodite foi então logo recebida e admirada pelas deusas Horas e Graças, que imediatamente a vestiram com uma túnica reluzente, a adornaram com muitas joias: como anéis, colares, braceletes. Pentearam seus lindos cabelos dourados e colocaram sobre sua cabeça um fascinante diadema de ouro. A mais nova bela deusa do mundo foi, portanto, enfeitada com os mais requintados ornamentos, pelas mãos mais dignas que podia existir na época à altura de uma deusa. Afrodite já preparada, arrumada, feliz e orgulhosa, caminha pela natureza, sentindo e percebendo o quanto era grandiosa a sua beleza e a força de sua graça, até o sol lançava seus raios com brilho especial em seu caminho.

As duas deusas que serviram de assessoras para Afrodite, Graças e Horas, colocaram a bela moça sentada dentro de uma linda e macia nuvem, providenciada por elas mesmas e a conduziram até o Olimpo, a ser apresentada aos outros deuses. Estes quando se depararam com tamanha beleza ao olharem para Afrodite, tiveram a sensação de que o brilho da deusa ofuscara seus olhos a ponto de turvar a visão, porém, em se tratando de deuses, rapidamente se recuperaram e identificaram a deusa da beleza e do amor.

No ensejo, assim sendo, os deuses logo se apressaram em recebê-la, todos queriam dar as mãos em cumprimentos à deusa, falar com ela e desfrutarem de sua companhia. A deusa da beleza com satisfação estampada no semblante divino, respondia delicadamente, suas palavras eram meigas, entre doce sorrisos e olhar encantador, ora gestos sublimes com as mãos, assim a deusa impôs sua presença com fascínio e deslumbramento perante os deuses do Olimpo. A “Afrodite é a rainha eterna da beleza e a deusa do amor, que governa os corações dos homens” (MENELAOS STEPFANIDES, 2011, p.59)

Nesta instigante história lendária da mitologia grega sobre a deusa da beleza e do amor, consta de duas origens, ou seja, há duas Afrodite, narrada por Pausânias, um dos oradores do discurso sobre o amor na obra literária de Platão, O Banquete, verifica-se uma profundidade de Pausânias ao se tratar do assunto da beleza e do amor em si. Pausânias menciona que o amor é representado como um Eros louvável e outro desprezível, o louvável é voltado para a alma e o desprezível voltado para o corpo, como Eros foi gerado na ocasião do nascimento de Afrodite, ele está sempre em busca do belo. "O amor é Eros, um daímon, um ser intermediário entre deuses e homens, entre mortais e imortais” (Banquete 202c) se há duas Afrodites, é certo que há dois Eros, já que Eros é escudeiro de Afrodite. 
Fazendo ainda menção ao discurso de Pausânias, ele narra que Afrodite, a mais antiga, a mais conhecida, filha de Urano, a deusa sem mãe (améter) nascida no início do Panteão Olímpico, era também chamada de Afrodite Urânia, que é o amor celestial, o amor espiritual, amor pela virtude e esta seria cercada e acompanhada por um Eros espiritual também, o qual inspira com suas flechas o amor à justiça, o amor à fraternidade, o amor à humanidade. A segunda deusa mencionada com o mesmo nome tratase da Vênus Pandêmia, seria uma deusa popular, do povo, filha dos deuses Zeus e Dione, uma ninfa inclusive, essa deusa é chamada de Afrodite Pandêmia, considerada uma deusa menor, que representa o amor mundano, deusa da sexualidade, venerada pelo povo, portanto, acompanhada também por um Eros popular, vulgar, grosseiro, que com suas flechas, inspira o amor pelos corpos, pelo desejo apenas, e esse amor quando levado às últimas consequências, ou seja, se o homem é inspirado, tocado pelas flechas do Eros vulgar, somente, esse homem toma o amor apenas como expressão dos seus instintos em busca de sua satisfação.

Porém, é venerado, que a finalidade do amor, a princípio, é o amor que transcende, amor à alma, à virtude, não seria para gerar satisfação instintiva ou prazer carnal, mas sim para gerar felicidade ( $\varepsilon \dot{\delta} \delta \alpha \mu o v i \alpha$ ), no entanto, a felicidade estaria em um plano, em um grau muito maior, mais elevado, do que apenas satisfação imediata das necessidades físicas do homem. Haja vista, que hoje, graças aos amantes vulgares, o amor é tão pouco valorizado, um capricho apenas.

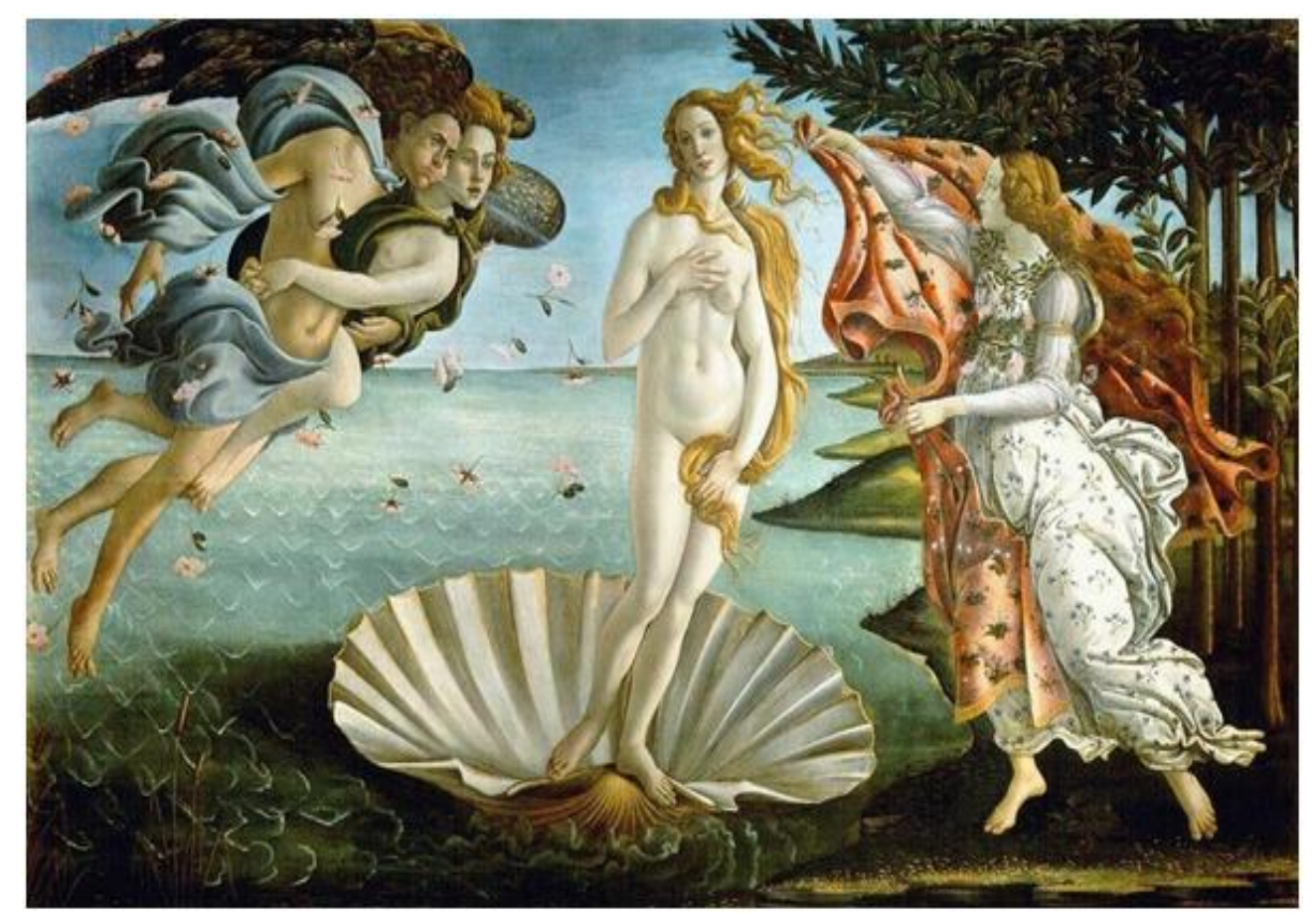

O Nascimento de Vênus, criado entre 1482 e 1485, é de autoria do pintor italiano Sandro Botticelli (1445-1510). 


\section{CONTRAPONDO-SE A BELEZA NA CONTEMPORANEIDADE}

É tamanha a força dominadora que o mito da beleza, impõem sobre as mentes femininas, o qual de fato chama a atenção, pois falando da década de 1990, quando aparecem as obras literárias de feministas como Susan Faludi e Naomi Wolf, o feminismo soava como um palavrão. Era notório o sentimento negativo das pessoas, de maneira geral, se alguma mulher reclamasse do mito da beleza, era porque, a mesma, sofria algum defeito, certamente essa mulher estaria acima do peso, obesa, era feia e incapacitada de satisfazer o prazer e o desejo de um homem, já que o ideal de beleza da época, suposto pela mídia de massa era uma mulher esquelética, porém com seios enormes, avantajados, peça rara na natureza, na ocasião, a importância que se dava a esse estereótipo de beleza, era algo acima de qualquer questionamento.

Naomi relata que muitas vezes em suas palestras, ela se surpreendia quando tentava alertar seu público dos riscos que os procedimentos estéticos ofereciam, por exemplo os perigos dos implantes mamários, as respostas que recebia da plateia pareciam inusitadas: "saída direto de O Banquete de Platão, o famoso diálogo sobre ideais eterno e imutáveis" (Naomi Wolf, 2019,p.15). O mito da beleza estava tão bem formatado nas pessoas, que não se percebia na época, que os ideais de beleza, não vinham do céu, mas que servia e atendia um projeto milionário de ordem financeira, o qual, visava apenas o lucro, que movimentava e sustentava a mídia, que por sua vez era a responsável por criar e disseminar os ideais da beleza. Por conseguinte, esse mito de beleza doutrinário, fazia as mulheres reféns, sem que elas mesmas se dessem conta.

Afinal essas mulheres Pandêmias do século XXI, bombardeadas psicologicamente por um sistema monetário, onde visa apenas o ganho de dinheiro, o real sentido da beleza passa longe, haja vista que, a beleza natural feminina se assemelha à beleza da deusa Pandêmia, em relação a aparência do corpo, a deusa venerada pelos homens, porém a deusa Afrodite Pandêmia é acompanhada de um escudeiro, Eros, que com suas flechas movimenta o amor, o interesse à beleza, aos corações dos homens, o que passa longe e não pode ser comparado com as flechas perversas do capitalismo, que, de maneira inversa, fere as próprias deusas do século XXI.

Em busca pela perfeição os padrões de beleza se transformam, e seguem o momento histórico vivido. A estatueta de Vênus Willendorf, datada da Pré-História, retrata uma idealização do corpo da mulher diferente, com seios tão grandes que caem por cima da barriga, uma barriga imensa que quase esconde a vagina, representando uma mulher bem preparada para a maternidade - o maior atributo que o sexo feminino poderia ter na época. 


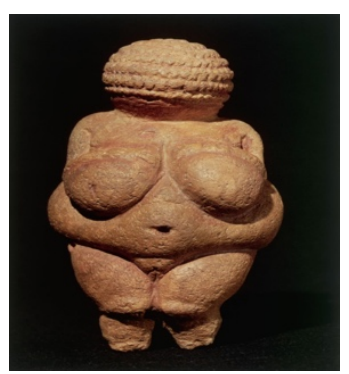

Vênus de Willendorf, $11 \mathrm{~cm}$ - Museu de História Natural de Viena (Áustria)

A beleza ideal é ideal porque não existe, porém, a busca incessante das mulheres continua impulsionando a demanda por procedimentos estéticos, sendo responsáveis por 86,4\%, ou 20.207.190, dos procedimentos em todo o mundo. As cinco intervenções mais populares entre as mulheres são o implante de mamas (prótese de silicone), lipoaspiração, blefaroplastia, abdominoplastia e mastopexia. Em 2017, os homens representaram 14,4\% dos pacientes estéticos (um pequeno aumento em relação a 2016), com 3.183.351 procedimentos realizados mundialmente. As cinco intervenções mais requisitadas entre os homens são blefaroplastia, ginecomastia, rinoplastia, lipoaspiração e transplante capilar.

Segundo o Presidente da Sociedade de Cirurgia Plástica e Estética (ISASP) o Dr. Renato Saltz, comenta:

É ótimo ver a divulgação dos resultados de 2017 e verificar o crescimento contínuo da cirurgia plástica e dos procedimentos estéticos em muitos países diferentes ao redor do mundo. Os Estados Unidos continuam na liderança, seguidos de perto pelo Brasil! Será muito interessante comparar esses dados com os resultados de 2018, já que estamos verificando um número recorde de pacientes aproveitando as últimas inovações em cirurgias estéticas para melhorarem a aparência e se sentirem bem. (sítio eletrônico, acessado e 20 de julho de 2019).

Para a Naomi Wolf (2019, p.29) A "beleza” não é universal, nem imutável, embora o mundo ocidental finja que as ideias de beleza feminina se originam de uma Mulher Ideal Platônica. O povo maori admira uma vulva gorda, e o povo padung, seios caídos. Segundo Naomi Wolf, o mito da beleza nada tem a ver com as mulheres, mas gira em torno das instituições masculinas e poder institucional dos homens. Embora sempre tenha existido o mito da beleza na história, desde os primórdios do patriarcado, o mito da beleza moderno, toma força, pois a mulher moderna contemporânea, vive sob pressão contínua com um ideal físico belo que não existe, porém muito difundido, disseminado pela tecnologia moderna, esse mito ganha espaço após a as convulsões sociais da industrialização. Sob esse conceito, ainda hoje, o mito da beleza condiciona as mulheres na necessidade da cultura, da economia e na estrutura do poder contemporâneo e cria uma contra ofensiva às mulheres.

Naomi propõe que a mulher escolha a aparência que ela desejar ter ou o que ela deseja ser, porém, jamais a obediência, as quais, o mercado da indústria multimilionária a impõe. 


\section{CONSIDERAÇÕES FINAIS}

Esse estudo aborda uma ideia geral do assunto beleza desde o surgimento do mito, visto que, na antiguidade, os gregos cultuavam seus mitos em busca de explicações às suas curiosidades, como para responder os problemas da existência e origem da vida. Para representar a beleza, não fora diferente; nasce o mito de Afrodite, que apresenta a beleza ( $x \dot{\alpha} \lambda \lambda \mathrm{os})$ esse conceito de beleza platônico, permeia o belo e o bem e aborda uma profundidade metafísica, a qual a beleza atinge uma ideia transcendente em

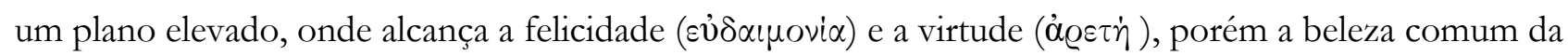
mulher, apreciada pelos homens, também explicada pelo mito da deusa da beleza, Pandêmia ,a qual representa os desejos pelo corpo, essa beleza, muitas vezes é mal compreendida, ora é buscada para a satisfação instintiva do homem, ora escraviza a mulher na ânsia de atingir padrões "perfeitos" dados por meios de comunicação de massa, como se fosse do ideal divino.

Haja vista que, a beleza permeia entre o amor e a sedução, cabe ao espectador conduzir o seu Eros, tanto para valorizar a beleza e vivenciar o amor, como para chegar ao mero prazer e as deusas protagonistas de suas aparências, escolherem entre a submissão mercantil, a serem livres como Pandêmia, irradiando beleza natural.

\section{REFERÊNCIAS}

ABBAGNANO, Nicola. Dicionário de Filosofia. São Paulo: Martins Fontes, 2007.

BRISSON, Luc. Introdução à filosofia do mito. 2 ed. ver e aum. São Paulo: Paulus, 2014.

JAEGER, Werner. Paideia: A formação do Homem Grego. São Paulo: Martins Fontes, 2003.

PLATÃO. O Banquete. Coleção Os Pensadores. São Paulo: Abril Cultural, 1972.

STEPHANIDES, Menelaos. Os Deus do Olimpo/ Menelaos Stephanides. Trad. Luiz Alberto Machado Cabral; ver. Téc. e notas: Luiz A. Machado; São Paulo: Odysseus, 2011.

WOOLF, N. O Mito da Beleza. Como as Imagens de Beleza são usadas contra as Mulheres. Tradução de Waldéa Barcellos. 5ªd. Rio de Janeiro. Ed. Rosa dos Tempos, 2019.

RENATO SALTZ. International Society of Aesthetic Plastic Surgery. Nova York, NY, 1 de Novembro de 2018. Disponível em: < https://www.isaps.org/wp-content/uploads/2018/11/2017-Global-SurveyPress-Release-br.pdf $>$. Acesso em: 20 de julho de 2019. 